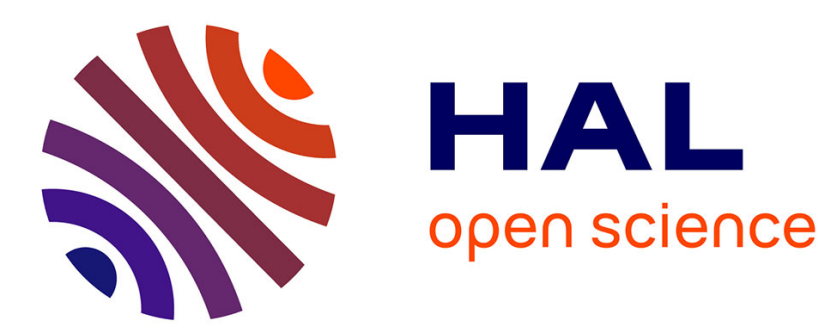

\title{
Perforation Behavior of 304 Stainless Steel Plates at Various Temperatures
}

Binsdu Jia, Alexis Rusinek, Slim Bahi, Richard Bernier, Raphaël Pesci, Amine Bendarma

\section{- To cite this version:}

Binsdu Jia, Alexis Rusinek, Slim Bahi, Richard Bernier, Raphaël Pesci, et al.. Perforation Behavior of 304 Stainless Steel Plates at Various Temperatures. Journal of Dynamic Behavior of Materials, 2019, 5 (4), pp.416-431. 10.1007/s40870-019-00208-9 . hal-02337472

\section{HAL Id: hal-02337472 \\ https://hal.science/hal-02337472}

Submitted on 29 Oct 2019

HAL is a multi-disciplinary open access archive for the deposit and dissemination of scientific research documents, whether they are published or not. The documents may come from teaching and research institutions in France or abroad, or from public or private research centers.
L'archive ouverte pluridisciplinaire HAL, est destinée au dépôt et à la diffusion de documents scientifiques de niveau recherche, publiés ou non, émanant des établissements d'enseignement et de recherche français ou étrangers, des laboratoires publics ou privés. 


\title{
Perforation Behavior of 304 Stainless Steel Plates at Various Temperatures
}

\author{
B. Jia ${ }^{1,2} \cdot$ A. Rusinek $k^{3,5} \cdot$ S. Bahi ${ }^{3} \cdot$ R. Bernier ${ }^{3} \cdot$ R. Pesci ${ }^{2} \cdot$ A. Bendarma ${ }^{4}$
}

\begin{abstract}
The effect of temperature on perforation behavior of 304 austenitic stainless steel plates was investigated experimentally. Perforation tests have been conducted at velocities from 80 to $180 \mathrm{~m} / \mathrm{s}$ and temperatures between -163 and $200{ }^{\circ} \mathrm{C}$. Low temperatures were obtained using a specific designed cooling device and the temperature distribution on the specimens was verified to be uniform. Based on the experimental results, the failure mode, the initial-residual velocity curves, the ballistic limit velocities and the energy absorption capacity under different temperatures were analyzed. It was found that petalling was the main failure mode during the perforation process. The average number of petals was three at $20^{\circ} \mathrm{C}$ or $200{ }^{\circ} \mathrm{C}$ and was increasing continuously to five at $-163{ }^{\circ} \mathrm{C}$. The ballistic limit velocity $V_{b l}$ was also affected by the initial temperature. It increased slightly from $93 \mathrm{~m} / \mathrm{s}$ at $200{ }^{\circ} \mathrm{C}$ to $103 \mathrm{~m} / \mathrm{s}$ at $-20{ }^{\circ} \mathrm{C}$ and then remained constant at lower temperatures. The material showed better energy absorption capacity at low temperatures and this came not only from the temperature sensitivity of the material but also from the strain-induced martensitic transformation effect. According to martensite measurement by X-ray diffraction technique, the martensite fractions along the fracture surface of petals were $87.1 \%, 66.2 \%, 52.8 \%$ and $32.4 \%$ respectively for initial temperatures of $-163^{\circ} \mathrm{C},-60{ }^{\circ} \mathrm{C},-20^{\circ} \mathrm{C}$ and $20^{\circ} \mathrm{C}$.
\end{abstract}

Keywords Perforation $\cdot$ Low and elevated temperatures $\cdot$ Failure mode $\cdot$ Energy absorption $\cdot$ Martensitic transformation

\section{Introduction}

As a representative of transformation induced plasticity (TRIP) steels [1, 2], 304 austenitic stainless steel (ASS) has high resistance to corrosion and oxidation as well as a unique combination of high strength and high ductility. Its beneficial mechanical properties come from strain-induced martensitic transformation (SIMT), which means that upon plastic deformation the initial austenite phase $(\gamma)$ transforms into stable martensite phase $\left(\alpha^{\prime}\right)$; thus both increased work hardening rate and significantly enhanced ductility can be achieved. These properties make 304 ASS extensively used in many areas such as civil engineering, navigation and transportation. During its working and manufacturing process such as liquid natural gas storage and transportation at low temperature $[3,4]$ and sheet metal forming at elevated temperatures $[5,6]$, it may be subjected to impact loading over a wide range of temperatures.

As impact loading is encountered from time to time in so many areas, a considerable amount of work has been done over the last decades to study the impact behavior of materials $[7,8]$. According to the projectile velocity, investigation on impact behavior of materials can be divided into 3 categories. The first category refers to low velocity impact $(<50 \mathrm{~m} / \mathrm{s})$, where thin plates are commonly perforated by a drop weight tower [9]. The second covers sub-ordnance and ordnance velocity range between 50 and $1300 \mathrm{~m} / \mathrm{s}$, where projectiles are usually accelerated by a compressed air gas 
gun to perforate or penetrate plates $[7,10,11]$. The last category refers to hypervelocity impact $(>1300 \mathrm{~m} / \mathrm{s})$, a velocity range often encountered in outer space impact such as debris hitting spacecrafts [12]. The second velocity regime aims at investigating the dynamic impact behavior of shell structures in many engineering areas and therefore has received the most attention. Mostly, sub-ordnance impact tests were performed with thin plates and non-deformable projectiles at room temperature to study its ballistic resistance performance, energy absorption capacity and failure mode. Those studies mainly focus on the influence of target thickness [13], impact obliquity [14], multilayer plates combination [15] and projectile nose shape [16-18] on perforation behavior of materials. Børvik et al. [13] investigated perforation and penetration behavior of Weldox 460E steel plates with target thickness varying between 6 and $30 \mathrm{~mm}$. The slope of the initial-residual velocity curves decreases with increasing target thickness and the target deformation mode changes from global deflection to shear localization. RodríguezMartínez et al. [19] found that the ballistic limit velocity of 304 ASS thin plates was affected by a combination of target thickness and projectile shape. Alavi Nia and Hoseini [15] compared ballistic resistance performance of monolithic, in-contact layered and spaced layered aluminum plates and found the monolithic target behaved the best. Børvik et al. $[16,18]$ conducted perforation tests of Weldox 460E steel plates using blunt, conical and hemispherical projectiles. It was found that both the energy absorption capacity and the failure mode of the material were affected by the projectile nose shape. The failure mode for the blunt projectile was shear banding while conical and hemispherical projectiles perforated the target by pushing the material aside, corresponding to a failure by ductile hole enlargement.

While material properties at low or elevated temperatures differ significantly from those at room temperature [20], quite a limited number of studies concerning perforation behavior of materials under various temperatures can be found. Mostly, the low temperature impact studies focus on hypervelocity impact of lightweight alloys and composites at around $-173{ }^{\circ} \mathrm{C}$ [21-24]. Also, with a specially designed drop weight tower, the low velocity impact behavior of AA 2024-T3 aluminum and TRIP 1000 steel at $-60{ }^{\circ} \mathrm{C}$ was investigated by Rodríguez-Martínez et al. [25, 26]. As for studies concerning impact behavior of materials under subordnance or ordnance velocity at different temperatures, high temperature perforation by several authors were found [27-30]. Rusinek et al. [27] developed a heating chamber coupled to the ballistic impact device to investigate perforation behavior of poly(methyl methacrylate) (PMMA). With the thermal chamber, Klosak et al. [30] studied perforation behavior of brass alloy plates under temperatures ranging from 20 to $260{ }^{\circ} \mathrm{C}$. Results showed that the energy absorption capacity decreased with increasing temperature. There was also some changes in the petalling failure mode: the number of petals increased from 3 to 6 within the testing temperature regime. Liu et al. [28] investigated the ballistic performance of GH4169 alloy at temperatures ranging from 25 to $600{ }^{\circ} \mathrm{C}$. A similar conclusion was obtained: larger plastic deformation of specimens and lower ballistic limit velocities at higher temperature. For sub-ordnance and ordnance velocity impact of materials under low temperatures, so far as we know, has not been investigated yet in the open literature.

According to literature review above, although 304 ASS may suffer from impact loading over a wide range of temperatures, the sub-ordnance and ordnance velocity impact behavior remains unclear. The purpose of this study, therefore, is to study the effect of the initial temperature on the perforation behavior of 304 stainless steel. First, an original cooling device was developed to test the structure behavior at low temperatures, ranging from -163 to $-20{ }^{\circ} \mathrm{C}$. The temperature distribution along the specimen surface was measured and simulated to be sure about the uniform temperature distribution. Then, ballistic impact tests of 304 steel plates were carried out under temperatures from -163 to $200{ }^{\circ} \mathrm{C}$ using the newly developed cooling device and the heating chamber by Rusinek et al. [27]. The target thickness was $1.5 \mathrm{~mm}$ and the projectile velocity was varying between 80 and $180 \mathrm{~m} / \mathrm{s}$. The experimental setup allowed measuring the initial velocity $V_{0}$ and residual velocity $V_{R}$ curves of the 3D structure. In addition, martensite fraction in perforated specimens was measured by X-ray diffraction technique to explain the improved energy absorption capacity of 304 ASS at low temperatures.

\section{Material Behavior and Apparatus Description}

\section{Ballistic Impact Set-up}

Ballistic impact tests of 304 stainless steel were performed using a pneumatic gas gun shown in Fig. 1. During the tests, the projectile is launched using a pneumatic gas gun and goes through the gas gun tube. By changing the initial pressure $P_{0}$, the impact velocity $V_{0}$ of the projectile may change up to $180 \mathrm{~m} / \mathrm{s}$ for a mass of $29 \mathrm{~g}$.

A detailed description of the target fixation with holders is shown in Fig. 1b. The target is sandwiched tightly between two holders by eight screws. These holders are made of high strength steel to be sure that no plastic deformation occurs during the testing process. After the impact process, three states named no perforation, critical perforation and complete perforation may be observed. If a complete perforation occurs, a residual velocity $V_{R}$ is measured by a method 
Fig. 1 Schematic view of the ballistic impact device: (1) gun barrel, (2) initial velocity measurement, (3) target, (4) target holder, (5) residual velocity measurement, (6) projectile catcher

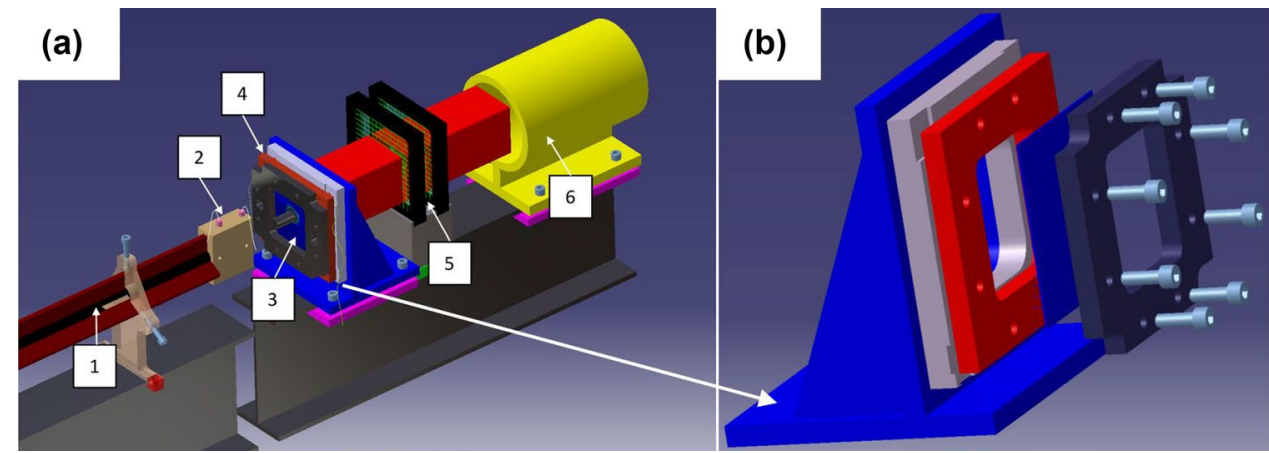

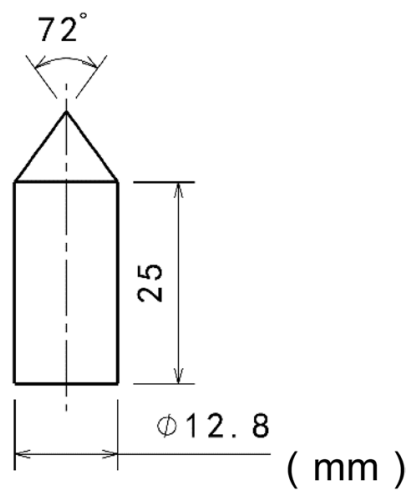

Fig. 2 Dimensions of the projectile, $m_{P}=29 \mathrm{~g}$

similar to the one described previously. Finally, the projectile catcher acts as a buffer to avoid damage.

Experimental results such as target deflection, fracture pattern and energy absorption capacity of materials are all influenced by the shape and mechanical properties of the projectile. Therefore, the dimensions and the mechanical properties of the projectile and of the target are introduced in the next section.

\section{Projectile and Target Description}

The dimensions of the projectile used in this study are shown in Fig. 2. It is a cylinder with a diameter of $12.8 \mathrm{~mm}$ and a height of $25 \mathrm{~mm}$ corresponding to a mass of $29 \mathrm{~g}$. At the top of the cylinder, a conical nose with an angle of $72^{\circ}$ is machined as reported in [31]. The projectile is made of Maraging steel with a hardness of $640 \mathrm{HV}$ and a yield stress of $2 \mathrm{GPa}$. The hardness and the strength are so high that the projectile is assumed to be rigid during experiments and numerical simulations.

The specimens were delivered as thin plates of $130 \mathrm{~mm}$ side length and $1.5 \mathrm{~mm}$ thickness. Their initial microstructure was $100 \%$ austenite phase. They were tightly fixed by the target holder to avoid sliding.

Ballistic impact of materials under low or elevated temperatures is encountered from time to time in many engineering areas such as liquefied natural gas (LNG) transportation and sheet metal forming. Hence, it is necessary and interesting to study temperature effect on the perforation behavior of materials. In the next section, the thermal chamber for high temperature testing is introduced.

\section{Thermal Chamber for High Temperature Perforation Tests}

In order to perform perforation tests at elevated temperature $\left(200{ }^{\circ} \mathrm{C}\right)$, a thermal chamber developed by Rusinek et al. [27] was adopted, Fig. 3. A furnace is used to heat up the air inside the chamber and then hot air is flowing around using a fan. By thermal conductivity and after a certain waiting time, the specimen reaches the expected temperature. Two thermocouples are fixed in the chamber: one to monitor the temperature inside the oven, another one on the center of the specimen to calibrate the temperature difference between the specimen and the air in the thermal chamber. In order to reach a uniform temperature distribution in the specimen, a waiting time of $20 \mathrm{~min}$ is imposed.

To cover perforation tests at not only elevated temperatures but also low temperatures, a cooling device for low temperature testing is developed and introduced in the next section.

\section{A Specific Cooling Device for Low Temperature Perforation Tests}

To conduct perforation tests at low temperatures, a cooling device has been designed and developed. As shown in Fig. 4a, the cooling box is fixed on the ballistic impact device. On one hand, the cold nitrogen gas flows from a liquid nitrogen tank through an aluminum pipe into the cooling box; on the other hand, the temperature inside the cooling box is monitored by a thermocouple connected to a temperature controller. Once the temperature inside the box reaches the set value, the temperature controller cuts off the power of the pump to stop the nitrogen gas flow. By this method, low temperatures between -90 and $-20{ }^{\circ} \mathrm{C}$ can be obtained. 

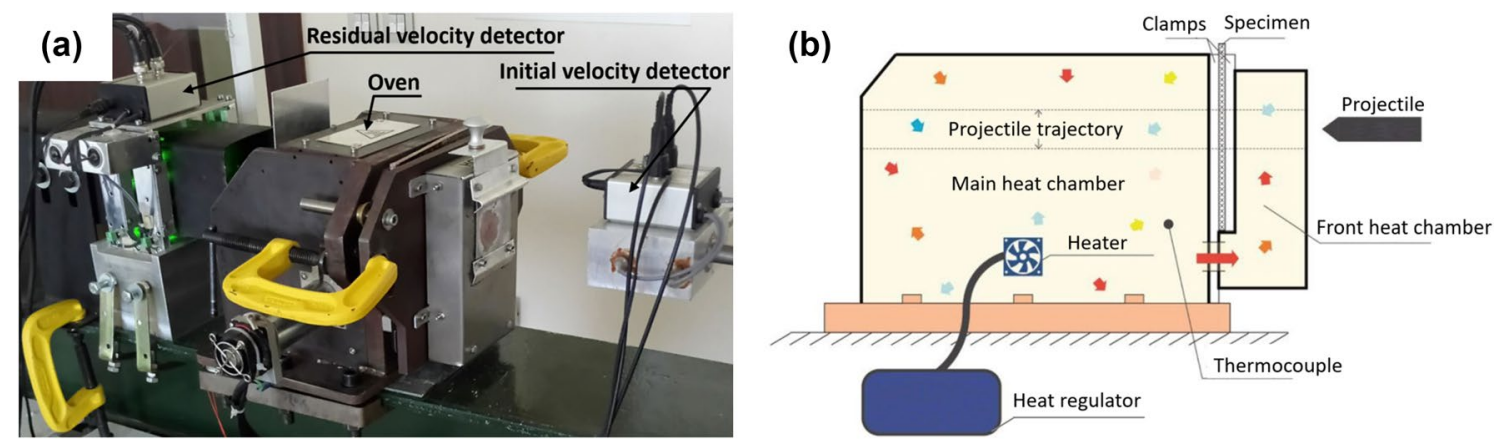

Fig. 3 Apparatus for high temperature perforation testing: a general view of the ballistic impact device and $\mathbf{b}$ schematic view of the thermal chamber [27]
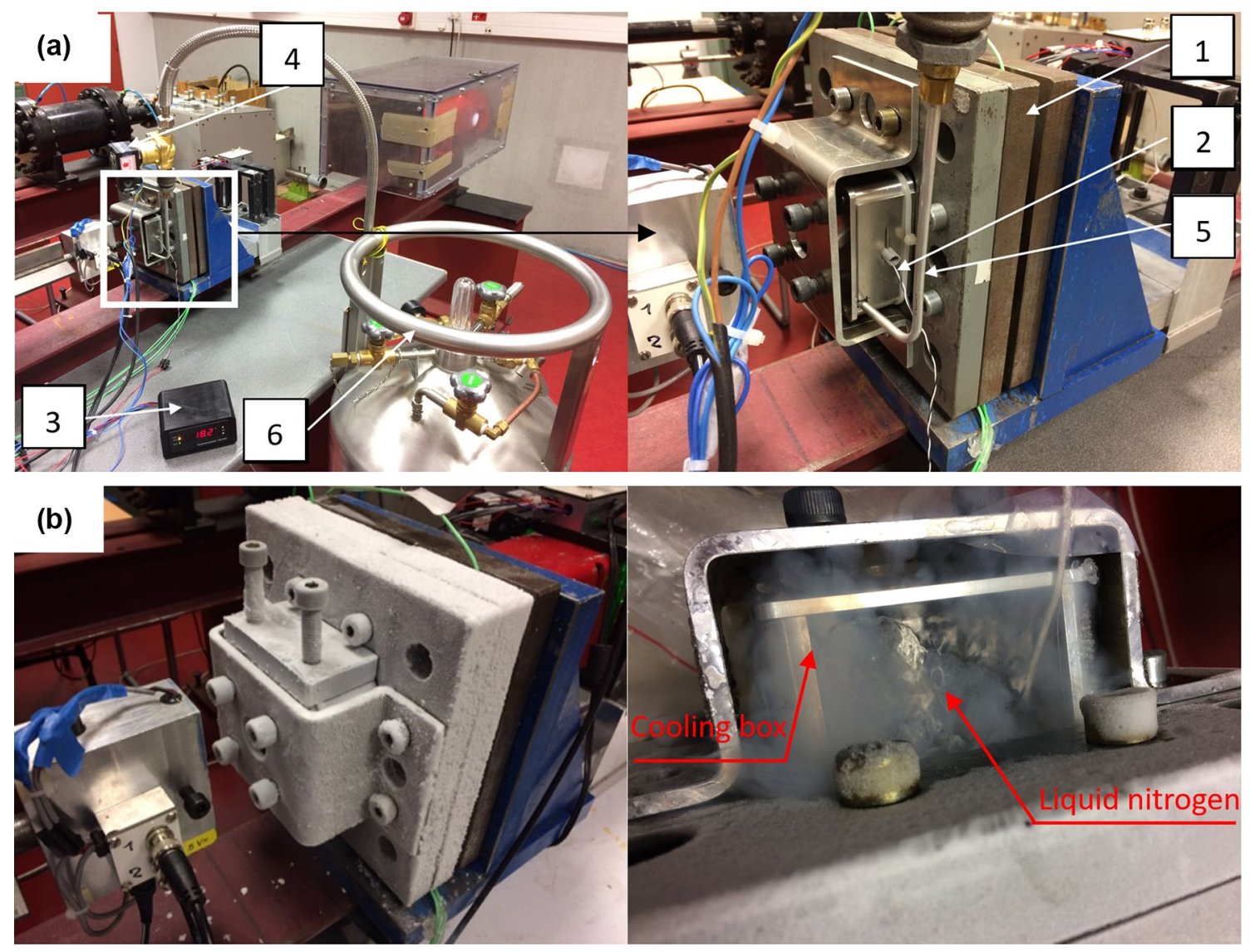

Fig. 4 Apparatus of the cooling device for testing: a between -90 and $-20{ }^{\circ} \mathrm{C}$ and $\mathbf{b}$ at $-163{ }^{\circ} \mathrm{C}$ : (1) ballistic impact device, (2) thermocouple, (3) temperature controller, (4) pump, (5) pipe, (6) liquid nitrogen tank

In addition, by filling the cooling box with liquid nitrogen directly, $-163{ }^{\circ} \mathrm{C}$ can be obtained, Fig. $4 \mathrm{~b}$.

The arrangement of the cooling device on the ballistic impact device is shown in Fig. 5. The 304 ASS plate is fixed on the target holder, then the cooling box is fixed on the target with a cooling box holder. The box is made of aluminum alloy to ensure a good heat transfer. In addition, four screws are used to apply a reduced force on the cooling box surface to ensure a correct contact between the plate and the cooling box. Therefore, the cooling box and the target are in tight contact with each other during the whole testing process.

Since the cooling device for low temperature perforation tests was newly developed, its reliability should be verified before testing. Unlike the device for high temperature 
Fig. 5 The arrangement of the cooling device on the ballistic impact device: $\mathbf{a}$ isometric view and $\mathbf{b}$ sectional view: (1) thermocouple, (2) pipe, (3) target, ing box, (6) target holder (4) cooling box holder, (5) cool-
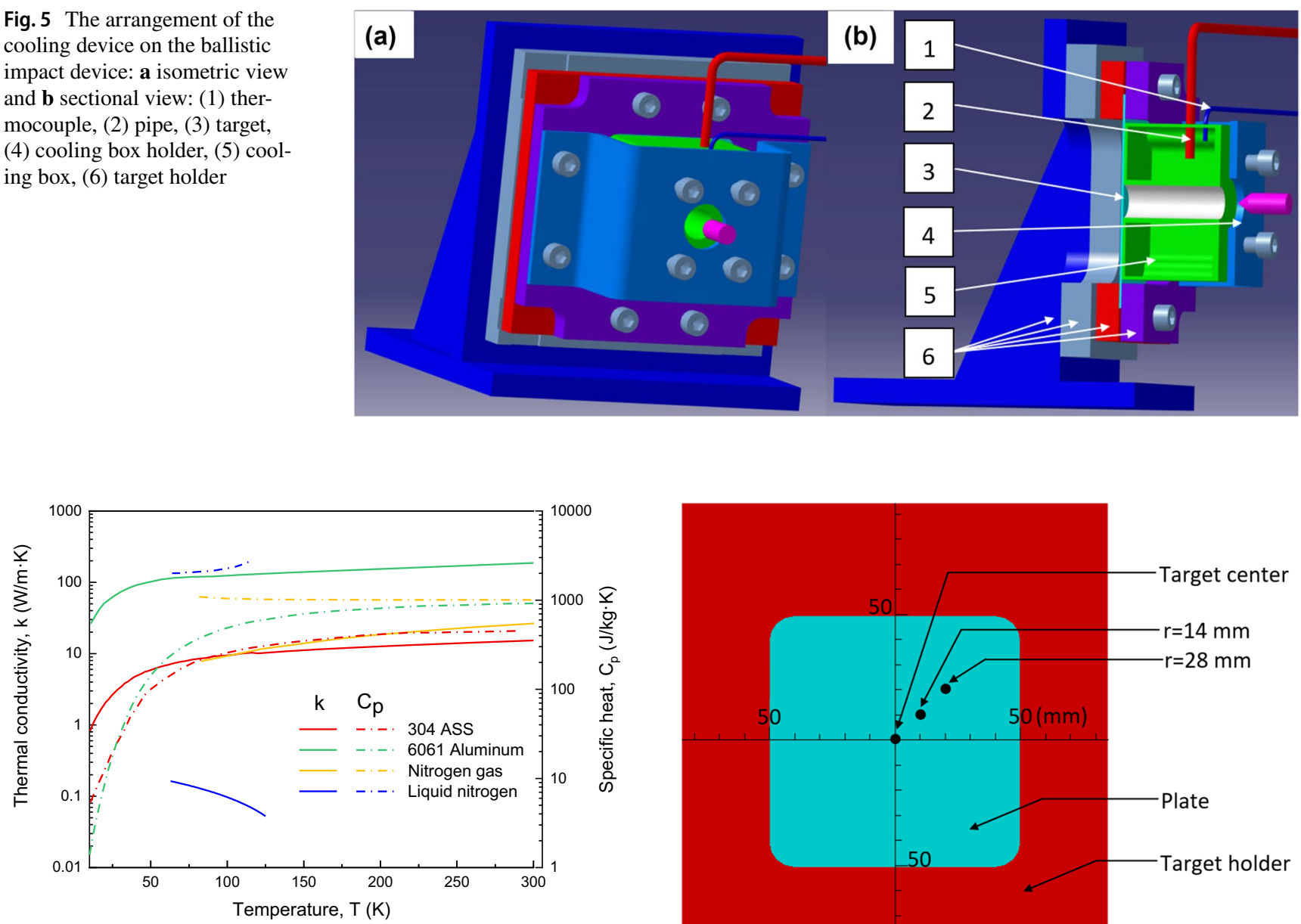

Fig. 6 Thermal conductivity $k$ and specific heat $C_{p}$ of the materials used in the numerical simulation [32]

perforation tests where the specimen is sealed firmly in a thermal chamber and a uniform temperature distribution is obtained easily, cryogenic temperatures present an experimental complexity to be performed, especially in terms of stabilization at extreme low temperatures, close to $-163{ }^{\circ} \mathrm{C}$. In addition, due to the decreasing thermal conductivity $k(T)$ and the specific heat capacity $C_{p}(T)$ under extreme low temperatures Fig. 6, it is important to verify that the impacted zone is deformed in a uniform temperature environment.

Therefore, in the next section, temperature distribution on the specimen is presented and further analyzed by a FEM model based on thermal heat transfer approach.

\section{Calibration and Heat Transfer Modeling of the Cooling Device}

To verify the reliability of the cooling device, the temperature evolution and distribution in the target are measured and analyzed. First, as shown in Fig. 7, the temperature

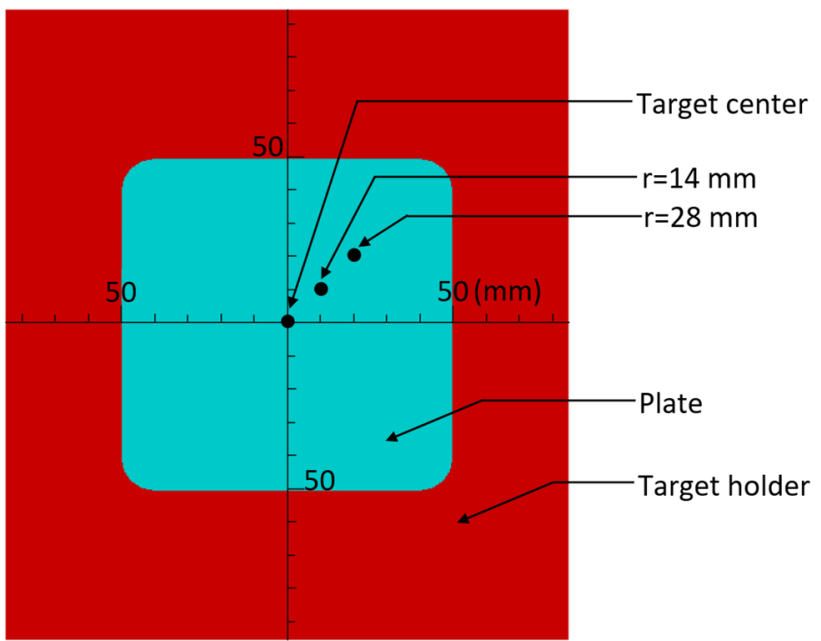

Fig. 7 Temperature measurement positions on the target surface: target center, $14 \mathrm{~mm}$ radius and $28 \mathrm{~mm}$ radius

of three radii on the target surface is measured (target center, $14 \mathrm{~mm}$ radius and $28 \mathrm{~mm}$ radius). The results are shown in Fig. 8; by setting temperatures of the coolant to be $-38{ }^{\circ} \mathrm{C},-64{ }^{\circ} \mathrm{C}$ and $-88^{\circ} \mathrm{C}$, the corresponding temperatures on the target surface are $-20{ }^{\circ} \mathrm{C},-40{ }^{\circ} \mathrm{C}$ and $-60{ }^{\circ} \mathrm{C}$, respectively. The temperature of $-163{ }^{\circ} \mathrm{C}$ is obtained directly by filling liquid nitrogen into the cooling box without using the temperature controller device. The temperatures of the three locations are not exactly the same with $T_{14 \mathrm{~mm}}<T_{\text {center }}<T_{28 \mathrm{~mm}}$ : it is due to the hole in the center of the cooling box, that is the path for the projectile to go through the cooling box and impact the target. Hence, the center of the target can not be cooled by surface contact with the cooling box and its temperature is slightly higher. In fact, within an area $56 \mathrm{~mm}$ in dimater, the maximum temperature fluctuation is only $4{ }^{\circ} \mathrm{C}$. As the projectile diameter is only $12.8 \mathrm{~mm}$, it can be assumed that the impacted zone is deformed in a uniform temperature environment. 

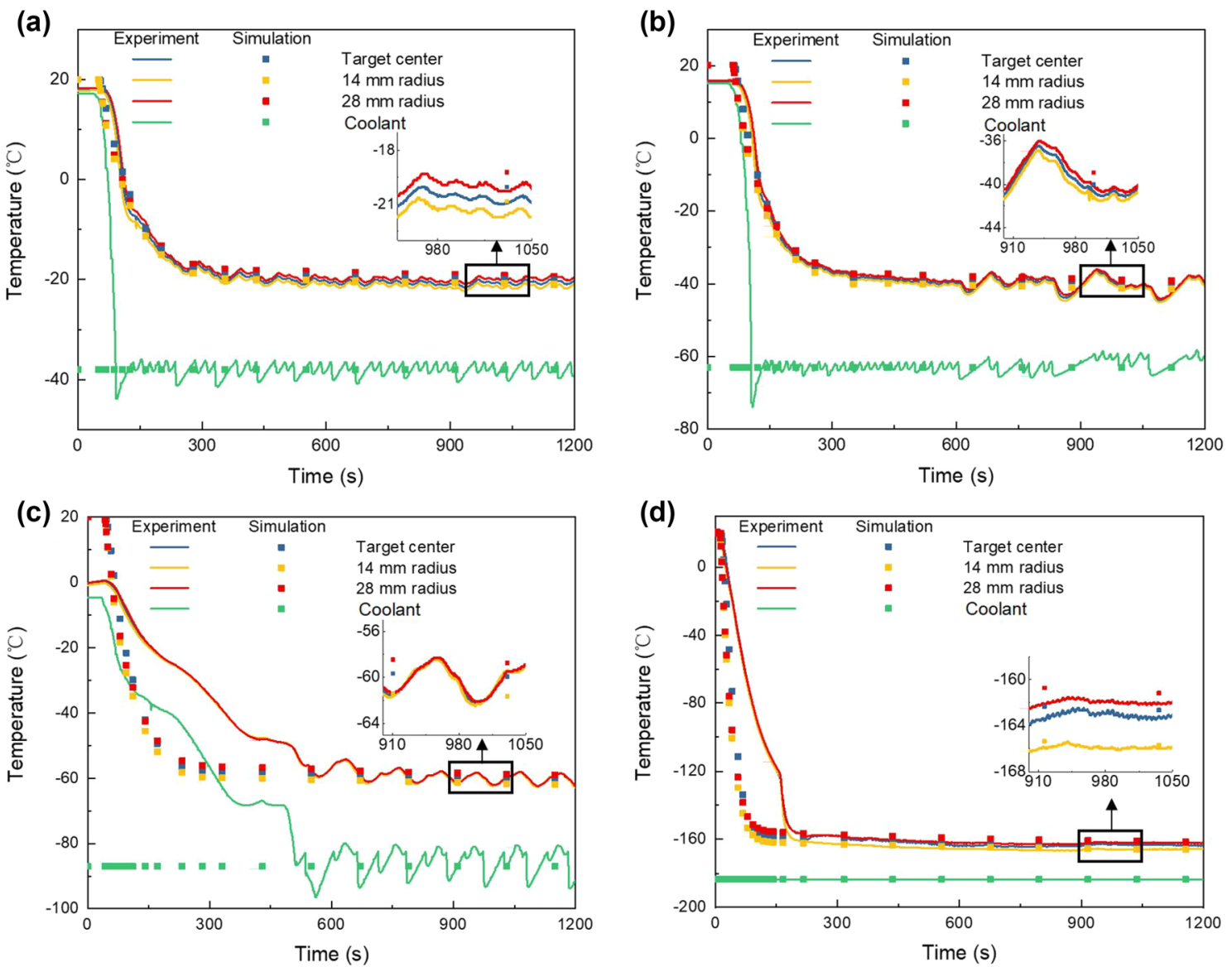

Fig. 8 Temperature distribution and evolution of the target with the coolant temperature set at: $\mathbf{a}-38{ }^{\circ} \mathrm{C}, \mathbf{b}-63{ }^{\circ} \mathrm{C}, \mathbf{c}-87^{\circ} \mathrm{C}$ and $\mathbf{d}-183{ }^{\circ} \mathrm{C}$

To analyze the temperature uniformity on the target in details, numerical simulation using COMSOL Multiphysics has been performed [27]. The thermal transfer is described by the generalized transient heat equation, Eq. 1 .

$\rho \cdot C_{p}(T) \cdot \frac{\partial T}{\partial t}-\nabla \cdot[k(T) \cdot \nabla T]=0$

The thermal conductivity $k(T)$ and the specific heat $C_{p}(T)$ of the materials used in the numerical simulation are shown in Fig. 6. The two parameters are strongly depending on the temperature, especially at very low temperatures.

The boundary conditions of the simulation are defined as follow, see Eq. 2 and Fig. 9:

- Natural convective heat flux $q_{c}$ on the free surface of the device.

- Forced convective heat flux $q_{f}$ through the inner free surfaces of the cooling box, due to the flow of the nitrogen gas.

- Thermal contact heat $q_{\text {int }}$ between different interface of contacts in the device.

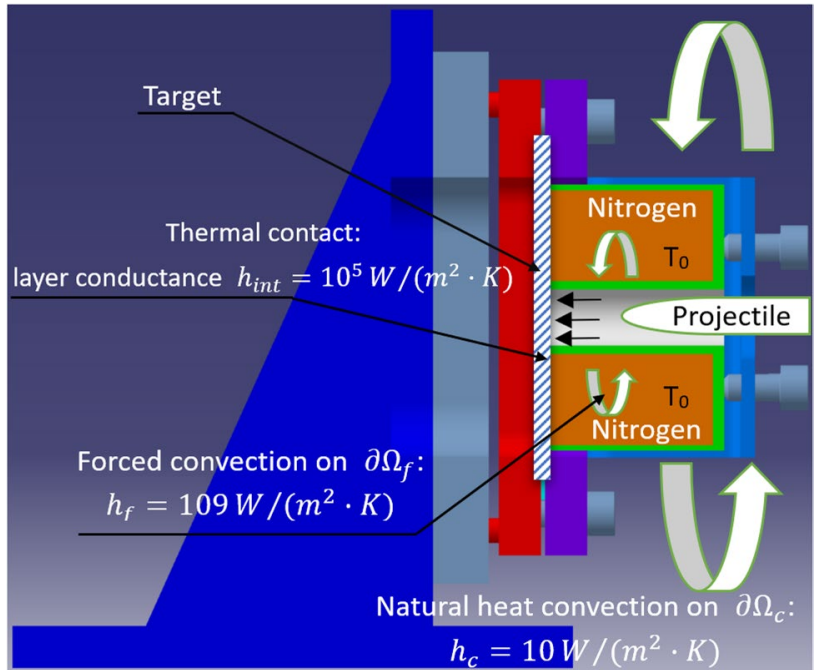

Fig. 9 Boundary conditions for temperature distribution analysis using COMSOL Multiphysics 
$\left\{\begin{array}{cl}q_{c}=-h_{c}\left(T-T_{0}\right) & \text { in } \partial \Omega_{c} \\ q_{f}=-h_{f}\left(T-T_{0}\right) & \text { in } \partial \Omega_{f} \\ q_{\text {int }}=h_{\text {int }}\left(T-T_{0}\right) & \text { in } \partial \Omega_{\text {int }}\end{array}\right.$

where $h_{c}=10 \mathrm{~W} /\left(\mathrm{m}^{2} \cdot \mathrm{K}\right), h_{f}=109 \mathrm{~W} /\left(\mathrm{m}^{2} \cdot \mathrm{K}\right)$ are the natural and forced heat convection coefficients, respectively. The conductance $h_{\text {int }}$ is equal to $10^{5} \mathrm{~W} /\left(\mathrm{m}^{2} \cdot \mathrm{K}\right)$.

The simulation results are shown as dots in Fig. 8. In Fig. 8a, b: the numerical results and experiments are in good agreement. In Fig. 8c, the experimental curve decreases slower than the simulated one as the flow speed of nitrogen gas is slightly smaller. But after a certain waiting time around $500 \mathrm{~s}$, the experimental values are consistent with the simulation results. In Fig. 8d, during the initial cooling stage, the experimental curve is comparatively higher. This is mainly because during experiments, it takes time to fill the cooling box with liquid nitrogen while it is assumed that the box is full of liquid nitrogen since the beginning of the simulation. In Fig. 8a-c, the temperature fluctuation caused by the temperature controller is observed. In fact, the delay of the temperature controller is set $3{ }^{\circ} \mathrm{C}$ and it causes a temperature fluctuation of $\pm 3^{\circ} \mathrm{C}$. In Fig. $8 \mathrm{~d}$, the target is cooled by filling the box with liquid nitrogen and the temperature fluctuation phenomenon is not observed any more.

Based on numerical simulation, it is observed that the temperature distribution on the target surface at $1200 \mathrm{~s}$ may be assumed as uniform in the impact zone Fig. 10. In fact, within the perforation zone, the maximum temperature differences in the four figures are $2{ }^{\circ} \mathrm{C}, 3{ }^{\circ} \mathrm{C}, 4^{\circ} \mathrm{C}$ and $8{ }^{\circ} \mathrm{C}$, respectively. For testing 304 ASS by a conical projectile, target deformation occurs mainly in the target center with a radius of $20 \mathrm{~mm}$. Under this condition, the maximum

\section{(a)}

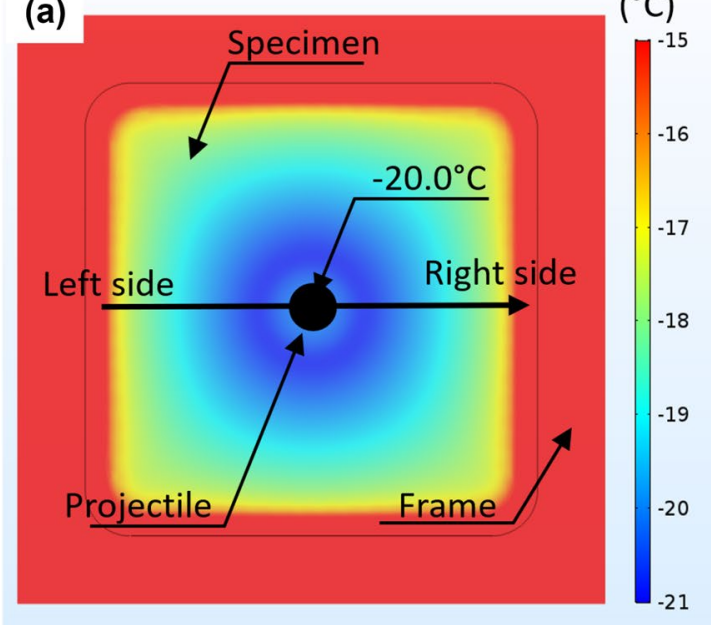

(c)

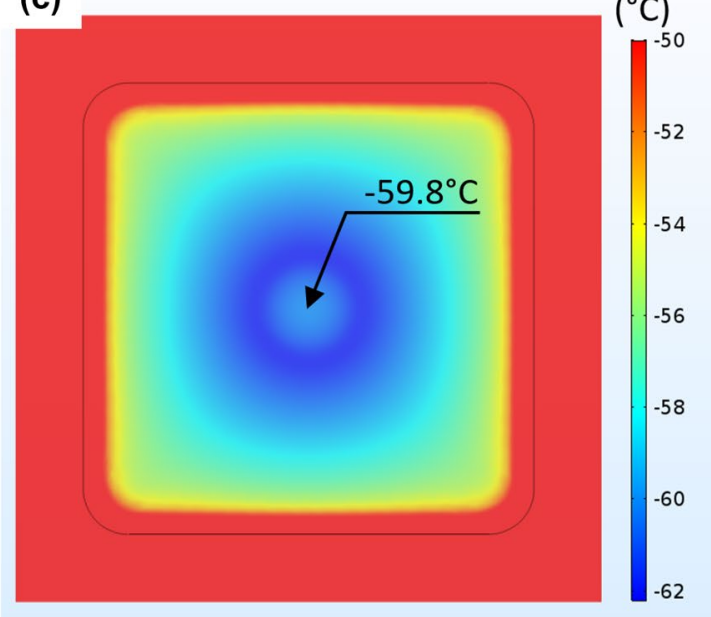

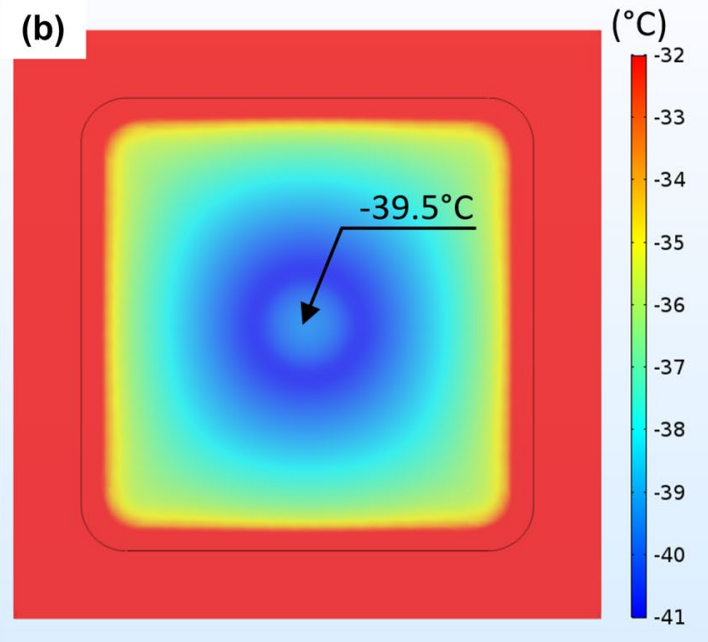

(b)

(d)

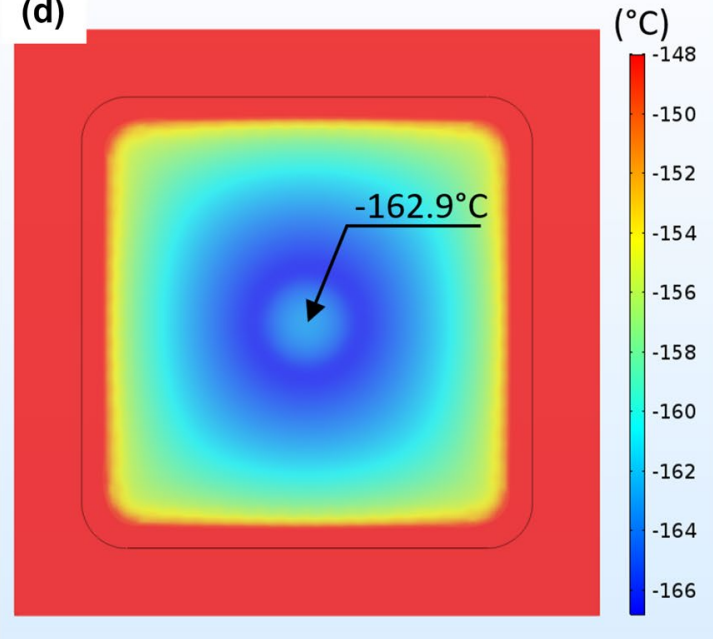

Fig. 10 Temperature distribution on target surface at $1200 \mathrm{~s}$ with the cooling box temperature set at: $\mathbf{a}-38{ }^{\circ} \mathrm{C}, \mathbf{b}-63{ }^{\circ} \mathrm{C}, \mathbf{c}-87{ }^{\circ} \mathrm{C}$ and $\mathbf{d}$ $-183^{\circ} \mathrm{C}$ 
temperature differences are $0.3{ }^{\circ} \mathrm{C}, 0.4{ }^{\circ} \mathrm{C}, 0.6{ }^{\circ} \mathrm{C}$ and $1.4{ }^{\circ} \mathrm{C}$, respectively. Therefore, the temperature distribution on the target surface is pretty uniform during the perforation process.

In addition, the temperature evolution from the left edge to the right edge of the target (the black line in Fig. 10a) is shown in Fig. 11. The temperature in the center of the target is slightly higher than the surrounding area, consistent with the experimental data in Fig. 8. Therefore, the simulation is in good agreement with experiments.

According to the temperature distribution analysis in this section, the temperature uniformity is obtained within the perforation area. Therefore, in the next section, perforation tests of 304 ASS under low, room and elevated temperatures are performed and the results are presented.

\section{Influence of Testing Temperature on the Perforation Process}

In this section, perforation experiments were performed by a conical projectile for five initial temperatures: $-163{ }^{\circ} \mathrm{C}$, $-60{ }^{\circ} \mathrm{C},-20{ }^{\circ} \mathrm{C}, 20{ }^{\circ} \mathrm{C}$ and $200{ }^{\circ} \mathrm{C}$. The tests were conducted over a wide range of initial impact velocities, ranging from 80 to $180 \mathrm{~m} / \mathrm{s}$, to obtain a complete ballistic curve of the material. Therefore, the effect of the initial temperature on the perforation process is analyzed.

\section{Effect of Testing Temperature on Failure Mode}

The influence of the initial temperature on the failure mode of 304 ASS is shown in Fig. 12. For the tests at $200{ }^{\circ} \mathrm{C}$, failure by ductile petalling, resulting from radial necking during the piercing process [33] is observed. A representative petal

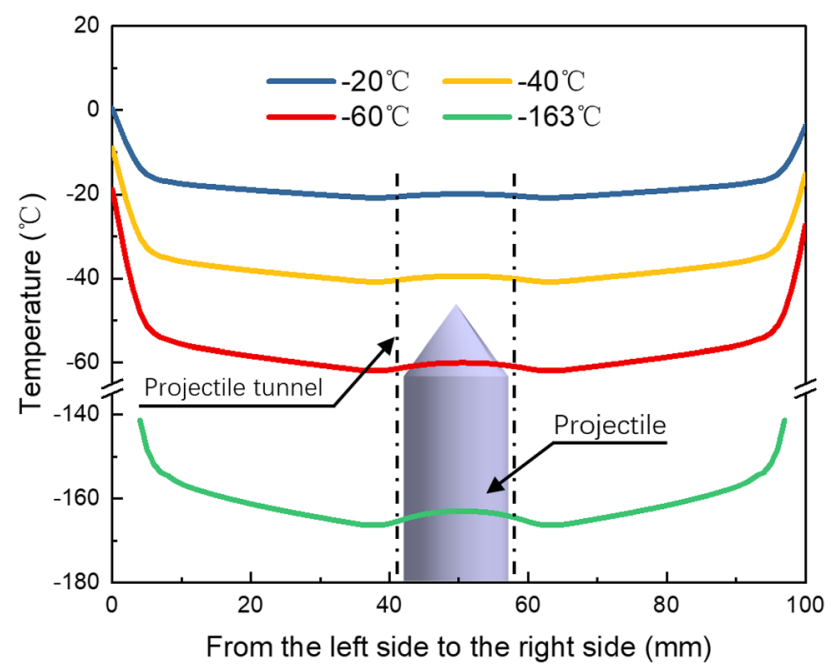

Fig. 11 Temperature from the left side to the right side of the target pattern of the material at $20{ }^{\circ} \mathrm{C}$ is shown in Fig. $12 \mathrm{~b}$, with a number of three triangle-shaped petals form. Compared to the petals formed at $200{ }^{\circ} \mathrm{C}$, the shape of petals at $20^{\circ} \mathrm{C}$ remain unchanged but the fracture surface becomes slightly rough. In addition, several secondary cracks are observed on the bigger petals; if the crack propagates until the end of the petals, failure pattern with four petals are observed. With a further decrease in testing temperature to $-20^{\circ} \mathrm{C}$, the average number of petals increases to four and the petal shape becomes irregular. One thing should be noticed is that no debris was found for the three testing temperatures above. Concerning perforation tests at $-60{ }^{\circ} \mathrm{C}$ and $-163{ }^{\circ} \mathrm{C}$, the breaking patterns become even rougher including debris ejection. The average number of petals increased continuously to five at $-163{ }^{\circ} \mathrm{C}$, higher than that of $-20{ }^{\circ} \mathrm{C}, 20^{\circ} \mathrm{C}$ and $200{ }^{\circ} \mathrm{C}$. The end of the petals became pretty rugged and discontinuous. Moreover, a lot of small cracks were observed on the petal surfaces.

Except failure pattern, the ballistic curve $V_{R}-V_{0}$ and the ballistic limit velocity $V_{b l}$ are also used to characterize the ballistic impact behavior of materials. In the next section, the evolution of $V_{R}-V_{0}$ curves and that of $V_{b l}$ with the testing temperature are presented.

\section{Effect of Testing Temperature on the Ballistic Curves $V_{R}-V_{0}$}

Results in terms of ballistic curves $V_{R}-V_{0}$ are presented in Fig. 13. The curves are then fitted to the relation proposed by Recht and Ipson [34], Eq. 3, in which the residual velocity of the projectile is calculated as a function of the initial velocity and the ballistic limit velocity.

$V_{R}=\left(V_{0}^{\alpha}-V_{b l}^{\alpha}\right)^{1 / \alpha}$

where $V_{0}$ and $V_{R}$ are the initial and residual projectile velocities, $V_{b l}$ is the ballistic limit velocity and $\alpha$ is a fitting parameter.

The ballistic limit velocities and fitting parameters for tests at different temperatures are given in Table 1. As shown in Fig. 13, the equation defines the ballistic curve shape properly. For testing at $-20{ }^{\circ} \mathrm{C},-60^{\circ} \mathrm{C}$ and $-163^{\circ} \mathrm{C}$, the ballistic limit velocity remains the same, $130 \mathrm{~m} / \mathrm{s}$. For testing at higher temperatures, $V_{b l}$ decreases with increasing temperature. At testing temperature of $200{ }^{\circ} \mathrm{C}$, the ballistic limit velocity is $93 \mathrm{~m} / \mathrm{s}$. While the ballistic limit velocity at $200{ }^{\circ} \mathrm{C}$ is lower than that at $20{ }^{\circ} \mathrm{C}$, the difference between the two curves decreases with increasing impact velocity. At ballistic impact velocities higher than $150 \mathrm{~m} / \mathrm{s}$, the two curves coincide. The fitting parameter $\alpha$ is also affected by testing temperature: the value at room and elevated temperatures is obviously lower than that at lower temperatures. A 

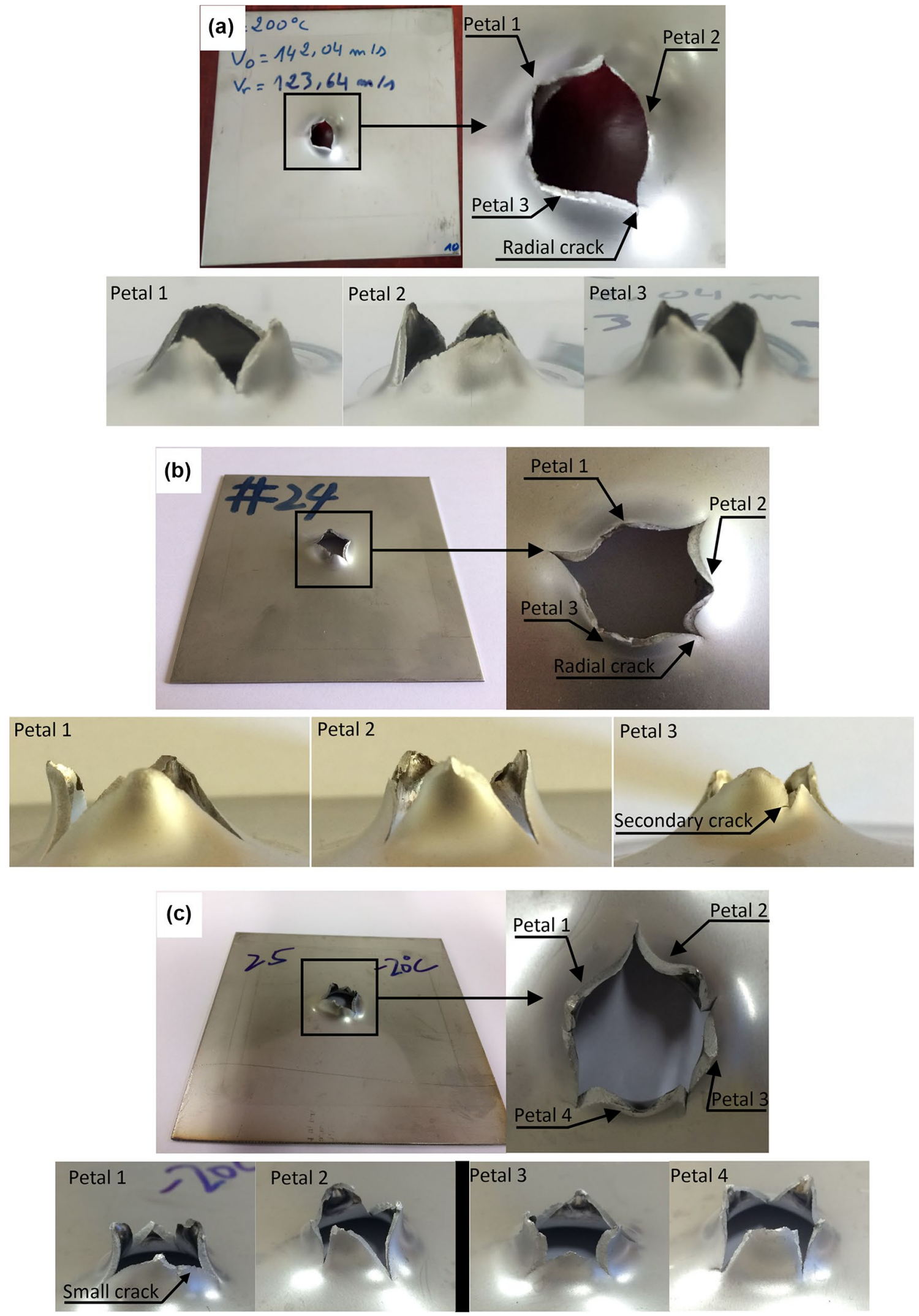

Fig. 12 Failure pattern for different testing temperatures: a $200{ }^{\circ} \mathrm{C}, \mathbf{b} 20^{\circ} \mathrm{C}, \mathbf{c}-20{ }^{\circ} \mathrm{C}, \mathbf{d}-60{ }^{\circ} \mathrm{C}$ and $\mathbf{e}-163{ }^{\circ} \mathrm{C}$ 

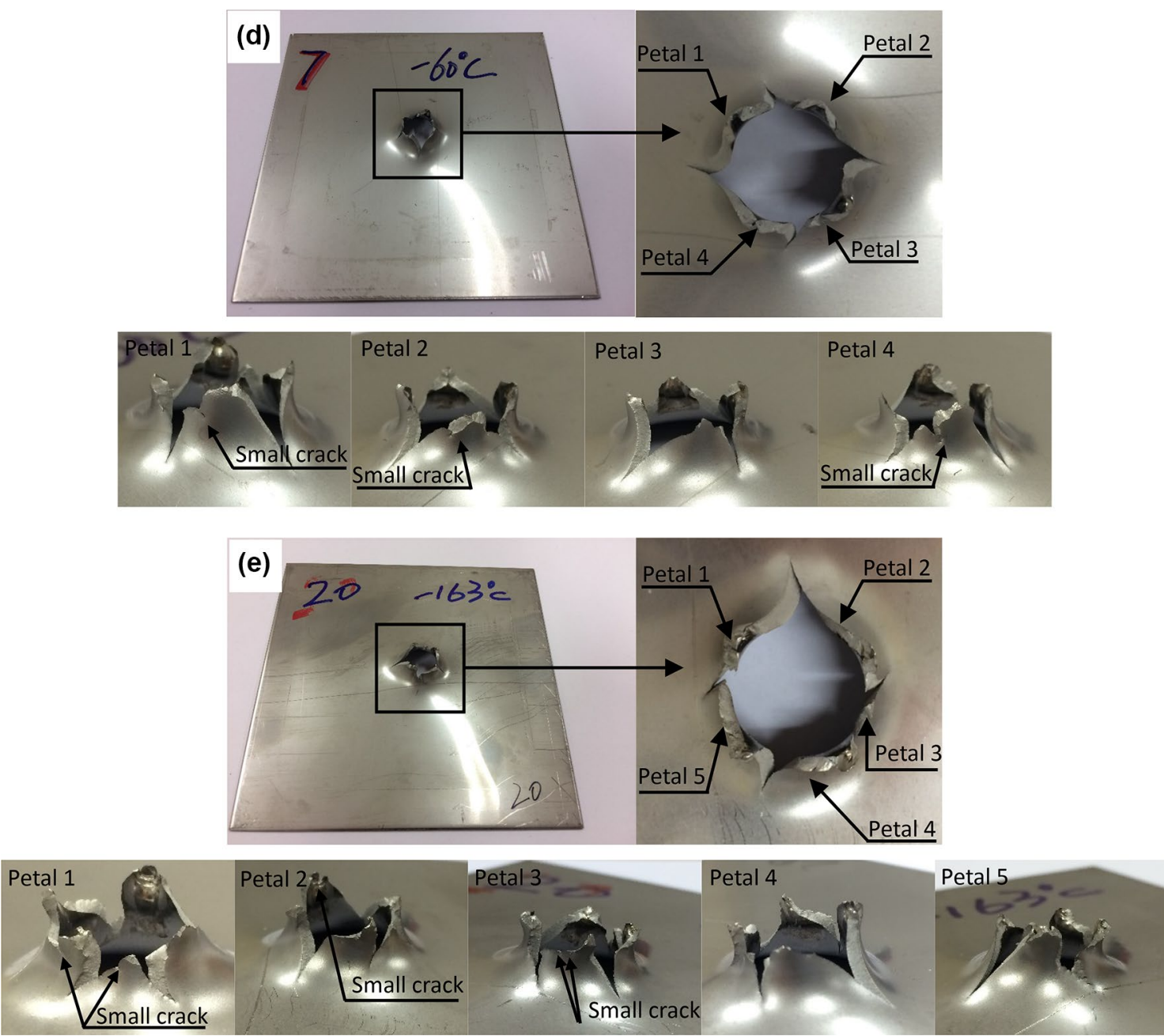

Fig. 12 (continued)

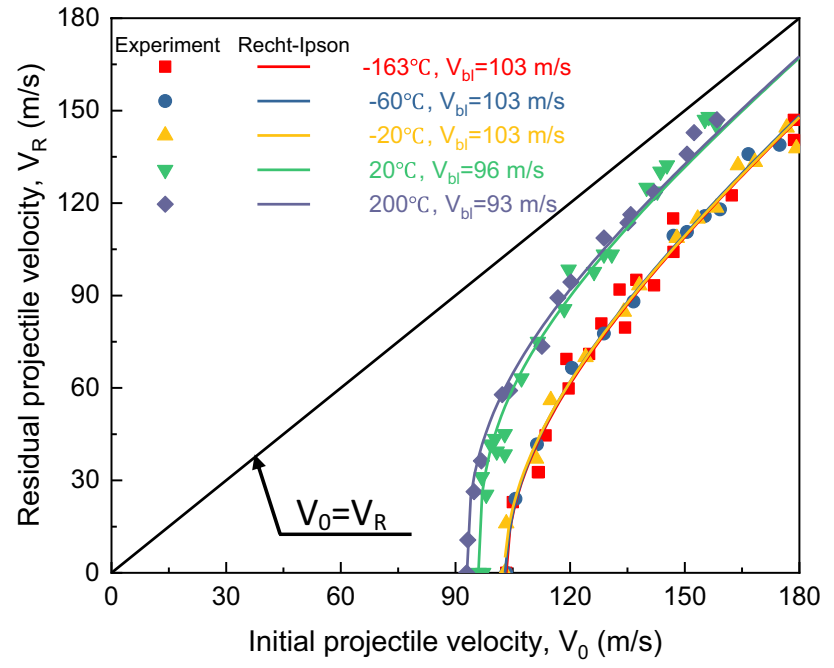

Fig. 13 Ballistic curves for $1.5 \mathrm{~mm}$ thick plates of 304 ASS impacted under different temperatures
Table 1 The ballistic limit velocities $V_{b l}$ and the fitting parameter $\alpha$ of 304 ASS under different testing temperatures

\begin{tabular}{lll}
\hline $\begin{array}{l}\text { Testing } \\
\text { temperature } \\
\left({ }^{\circ} \mathrm{C}\right)\end{array}$ & $V_{b l}(\mathrm{~m} / \mathrm{s})$ & $\alpha$ \\
\hline-163 & 103 & 2.006 \\
-60 & 103 & 2.028 \\
-20 & 103 & 2.005 \\
20 & 96 & 2.712 \\
200 & 93 & 2.660 \\
\hline
\end{tabular}

lower $\alpha$ means better impact resistance against projectile and higher ballistic limit velocity [18]. Therefore, the evolution of experimentally obtained $V_{b l}$ and $\alpha$ with testing temperature are consistent with each other.

Based on the ballistic curves $V_{R}-V_{0}$, the energy absorbed by the specimens can be calculated. In the next section, the effect of testing temperature and the initial 
projectile velocity $V_{0}$ on the energy absorption capacity of 304 ASS is analyzed.

\section{Effect of Testing Temperature on the Energy Absorption Capacity of 304 ASS}

During the perforation process, part of the kinetic energy of the projectile is absorbed by the plate. Knowing the initial projectile velocity $V_{0}$ and residual projectile velocity $V_{R}$, energy absorbed by the plate $W_{\text {Plate }}^{\text {Total }}$ can be calculated as follows:

$W_{\text {Plate }}^{\text {Total }}=\frac{1}{2} M_{p}\left(V_{0}^{2}-V_{R}^{2}\right)$

where $M_{p}$ is the mass of the projectile and equal to $29 \mathrm{~g}$.

A part of the kinetic energy, Eq. 4, is transfer to the plate during the process of impact or perforation. However and as discussed in [31, 32], the energy lost due to elastic deformation of the plate, friction between the projectile and the target and those transferred to the ejected debris can be neglected. Therefore, the energy absorbed by the plate is then written as follows:

$W_{\text {Plate }}^{\text {Total }}=\frac{1}{2} M_{p}\left(V_{0}^{2}-V_{R}^{2}\right)=W_{h}+W_{p b}+W_{p s}+W_{p}+W_{c}$

where $W_{h}$ is the dissipated energy as heat, $W_{p b}$ is the plastic bending energy of the target, $W_{p s}$ is the plastic stretching energy of the target, $W_{p}$ is the plastic bending energy of the petals and $W_{c}$ is the crack formation and propagation energy.

Energy absorption results as a function of $V_{0}$ for tests at different temperatures are presented in Fig. 14. First, energy absorption for tests at low temperatures $\left(-163{ }^{\circ} \mathrm{C},-60{ }^{\circ} \mathrm{C}\right.$

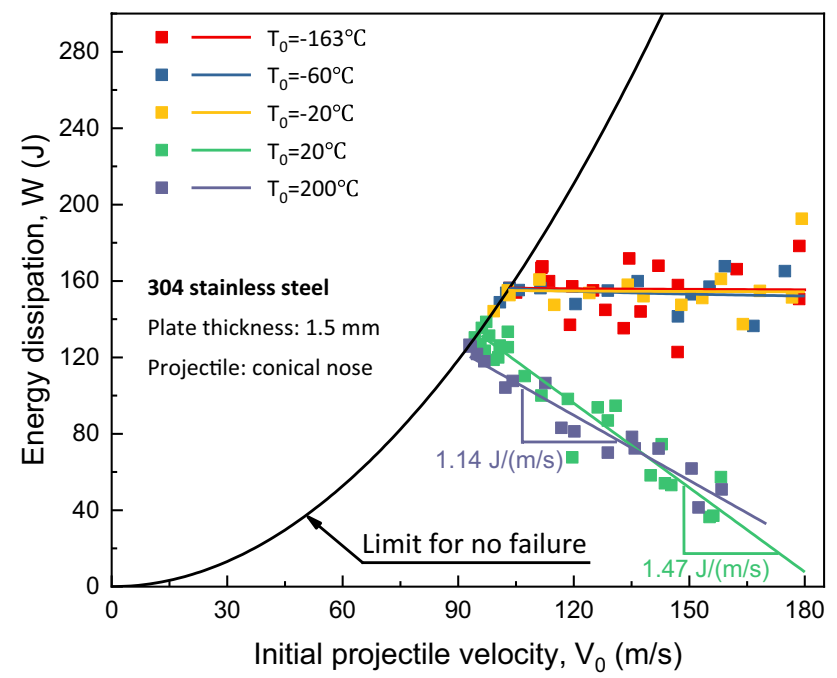

Fig. 14 Energy absorbed by the target as a function of the initial projectile velocity for different testing temperatures and $-20^{\circ} \mathrm{C}$ ) is significantly higher than at $20^{\circ} \mathrm{C}$, while energy absorption at $200{ }^{\circ} \mathrm{C}$ is the lowest. This is consistent with the fracture pattern observed: more petals and cracks at low temperatures. A similar phenomenon was observed during low velocity perforation test of TRIP 1000 steel by Rodríguez-Martínez et al. [26]: the ballistic limit velocity $V_{b l}$ changed from 2.6 to $3.1 \mathrm{~m} / \mathrm{s}$ when testing temperature decreased from 15 to $-60{ }^{\circ} \mathrm{C}$. According to the analysis of Rodríguez-Martínez, the improved energy absorption at low temperature came from temperature sensitivity of the TRIP 1000 steel and no martensitic transformation was observed during the perforation process.

Another interesting phenomenon concerning energy absorption capacity of 304 ASS is the evolution of the absorbed energy with impact velocity. For the tests at low temperatures $\left(-163{ }^{\circ} \mathrm{C},-60{ }^{\circ} \mathrm{C}\right.$ and $\left.-20^{\circ} \mathrm{C}\right)$, the initial projectile velocity $V_{0}$ does not affect the absorbed energy in the tested impact velocity range. In fact, the averaged energy absorption for the three previous temperatures are $156 \mathrm{~J}$, $154 \mathrm{~J}$ and $155 \mathrm{~J}$, respectively. However, for the tests at $20^{\circ} \mathrm{C}$ and $200{ }^{\circ} \mathrm{C}$, the absorbed energy decreases linearly with increasing impact velocity. Although the absorbed energy at $20{ }^{\circ} \mathrm{C}$ is slightly higher than that at $200{ }^{\circ} \mathrm{C}$, it decreases faster and becomes lower at impact velocities larger than $137 \mathrm{~m} / \mathrm{s}$.

As discussed using Eq. 5, a part of the kinetic energy is induced to the plate to generate no perforation, partial or complete perforation depending on the quantity transferred to it. In order to analyze the effect of temperature on energy absorption mechanisms of 304 ASS in more details, the permanent deflection and bending of the impacted specimens at different temperatures was measured, Fig. 15. It is clear that the target deflection increases with increasing testing temperature. Plastic bending of targets is larger at higher temperatures due to thermal softening [35]. Next, this view is further verified by petal thickness measurement.

To study the evolution of petal thickness with testing temperature, the perforated specimens at impact velocity around $146 \mathrm{~m} / \mathrm{s}$ were cut and then the thickness of the petals was measured. As shown in Fig. 16, with increasing testing temperature from -163 to $20{ }^{\circ} \mathrm{C}$, the thickness first remains constant at around $1.26 \mathrm{~mm}$ and then decreases continuously to $0.60 \mathrm{~mm}$ (the initial plate thickness $t_{0}$ was $1.5 \mathrm{~mm}$ ). A smaller thickness at high temperatures indicates a bigger plastic strain to fracture and therefore a larger plastic deformation of the specimens [36].

Although the plastic deformation of specimens declines with decreasing temperature, the targets absorb more energy at lower temperatures. Therefore, it is supposed that the improved energy absorption capacity of 304 ASS at low temperatures comes from its temperature sensitivity or the SIMT effect. According to martensite fraction measurement (presented in the next section), much martensite was found 
Fig. 15 Deflection of postmortem specimens tested at around $125 \mathrm{~m} / \mathrm{s}$ under different temperatures
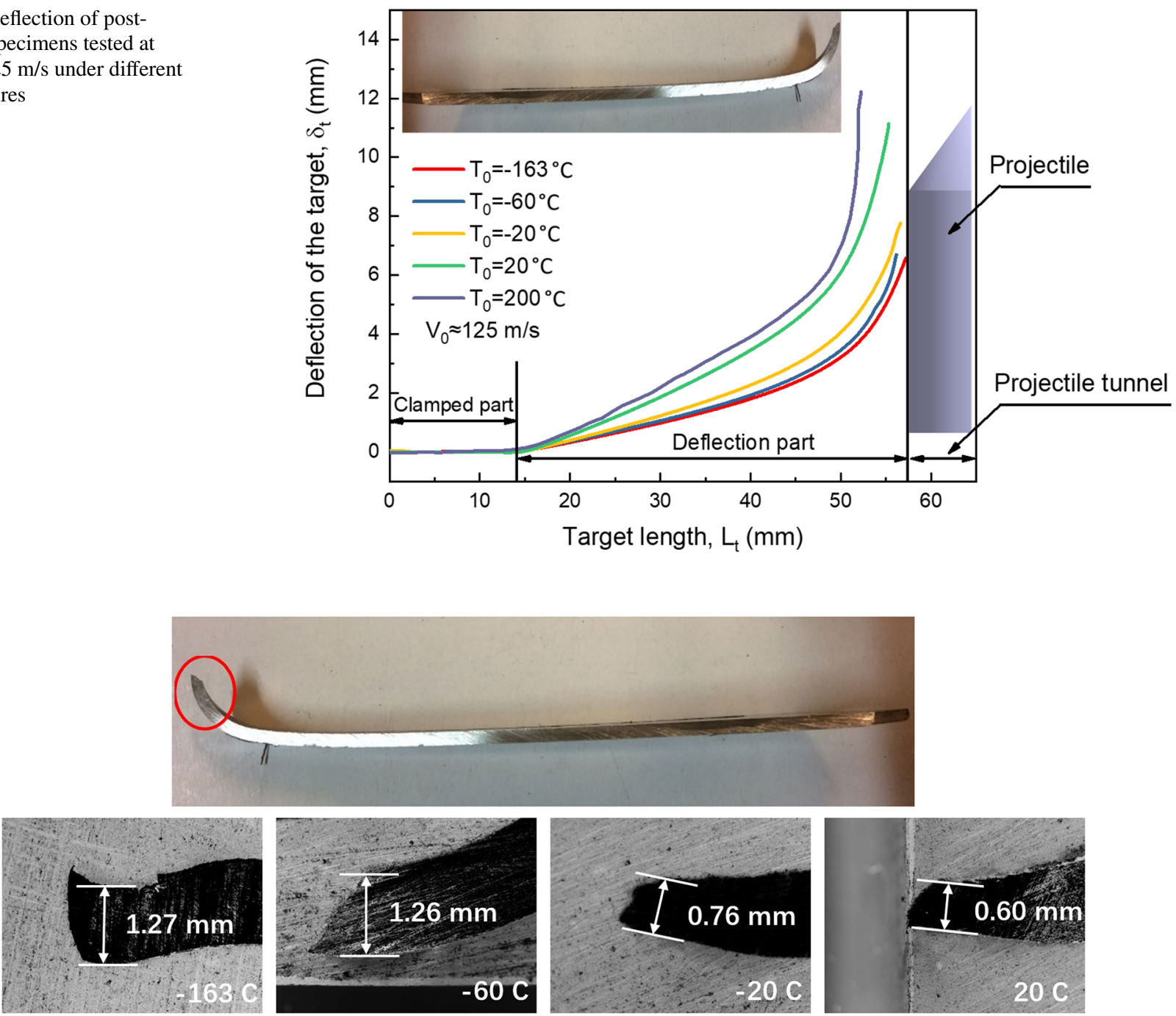

Fig. 16 Thickness of the petals under different initial testing temperatures, $t_{0}=1.5 \mathrm{~mm}$

in the petal area under low temperatures. Hence, different from the results of Rodríguez-Martínez et al. [26], the improved energy absorption of 304 ASS at low temperatures is related not only to the temperature sensitivity but also the SIMT effect.

\section{X-ray Diffraction Analysis of Specimens Perforated at Different Temperatures}

A notable phenomenon during the deformation process of 304 ASS is martensitic transformation. The transformation helps to increase not only the flow stress but also the ductility of the material. This phenomenon is often observed during quasi-static deformation tests of 304 ASS. However, studies concerning SIMT under impact loading are rarely published. To verify if martensitic transformation occurs during ballistic impact tests and also to study its influence on the perforation behavior of 304 ASS, martensite fraction in post-mortem specimens was measured by X-ray diffraction (XRD) technique.

\section{Determination of Phases Volume Fraction by X-ray Diffraction (XRD) Technique}

After perforation tests, the microstructure of specimens changed from pure austenite to a combination of martensite $\alpha^{\prime}$ (body-centered tetragonal phase) and austenite $\gamma$ (facecentered cubic phase). The volume fraction of each phase is proportional to the integrated diffraction peak intensity. Hence, using a portable PROTO goniometer and by comparing the integrated X-ray diffraction intensities of the two 
phases with the theoretical intensities, the volume fraction of each phase is determined by Eqs. 6-8.

$V_{\alpha^{\prime}}=\frac{I_{\alpha^{\prime}} / R_{\alpha^{\prime}}}{\left[\left(I_{\alpha^{\prime}} / R_{\alpha^{\prime}}\right)+\left(I_{\gamma} / R_{\gamma}\right)\right]}$

$V_{\gamma}=\frac{I_{\gamma} / R_{\gamma}}{\left[\left(I_{\alpha^{\prime}} / R_{\alpha^{\prime}}\right)+\left(I_{\gamma} / R_{\gamma}\right)\right]}$

$V_{\alpha^{\prime}}+V_{\gamma}=1$

where $I_{\alpha^{\prime}}$ and $I_{\gamma}$ are the integrated diffraction peak intensities of martensite and austenite phases, respectively. $R_{\alpha^{\prime}}$ and $R_{\gamma}$ are parameters depending on the phase composition, crystal structure, interplanar spacing (hkl) and the Bragg angle. Two peaks for each phase were considered: $\{211\}$ and $\{200\}$ for martensite, $\{220\}$ and $\{200\}$ for austenite [37].

\section{Effect of Testing Temperature on Martensitic Transformation of 304 ASS}

Martensitic transformation occurs in 304 ASS under certain conditions, it usually affects deformation and fracture behavior significantly. Martensite is often observed in austenite stainless steel under quasi-static strain rate or cryogenic temperatures [38-41]. However, for martensitic transformation under dynamic loading, few studies can be found [19, 42]. To investigate its influence on perforation behavior of 304 ASS, martensite distribution in perforated specimens under different temperatures was measured by X-ray diffraction technique. First, the plates impacted at around $146 \mathrm{~m} / \mathrm{s}$ under $-163{ }^{\circ} \mathrm{C},-60{ }^{\circ} \mathrm{C},-20^{\circ} \mathrm{C}$ and $20^{\circ} \mathrm{C}$ were cut, Fig. 17. The parameter $M_{d}$ is the temperature above which no martensitic transformation occurs even with large plastic deformation [43]: it is measured for our material to be $140{ }^{\circ} \mathrm{C}$. So there is no martensite formed under perforation tests at $200{ }^{\circ} \mathrm{C}$ (hence not considered). Then, martensite fraction on the fracture surface of the petals, Fig. 17a, and along the crosssection of the plates, Fig. 17b, was measured.

Martensite fraction on the fracture surface of the petals is shown in Fig. 18a. It is clear that the martensite fraction decreases with increasing testing temperature. A high amount of martensite of $87.1 \%$ was found at $-163{ }^{\circ} \mathrm{C}$ and this value decreases continuously to $32.4 \%$ at $20{ }^{\circ} \mathrm{C}$. As martensitic transformation is pretty sensitive to temperature, lower transformation rate at higher temperatures is often observed in quasi-static tension or shear tests [33, 34, 44, 45].

Martensite distribution along the cross-section of the plates is shown in Fig. 18b. Transformation occurs mainly in the petals and martensite fraction in the plate deflection part is comparatively lower. With increasing temperature from -163 to $20^{\circ} \mathrm{C}$, martensite fraction in the petal part decreases continuously but the value is almost constant in
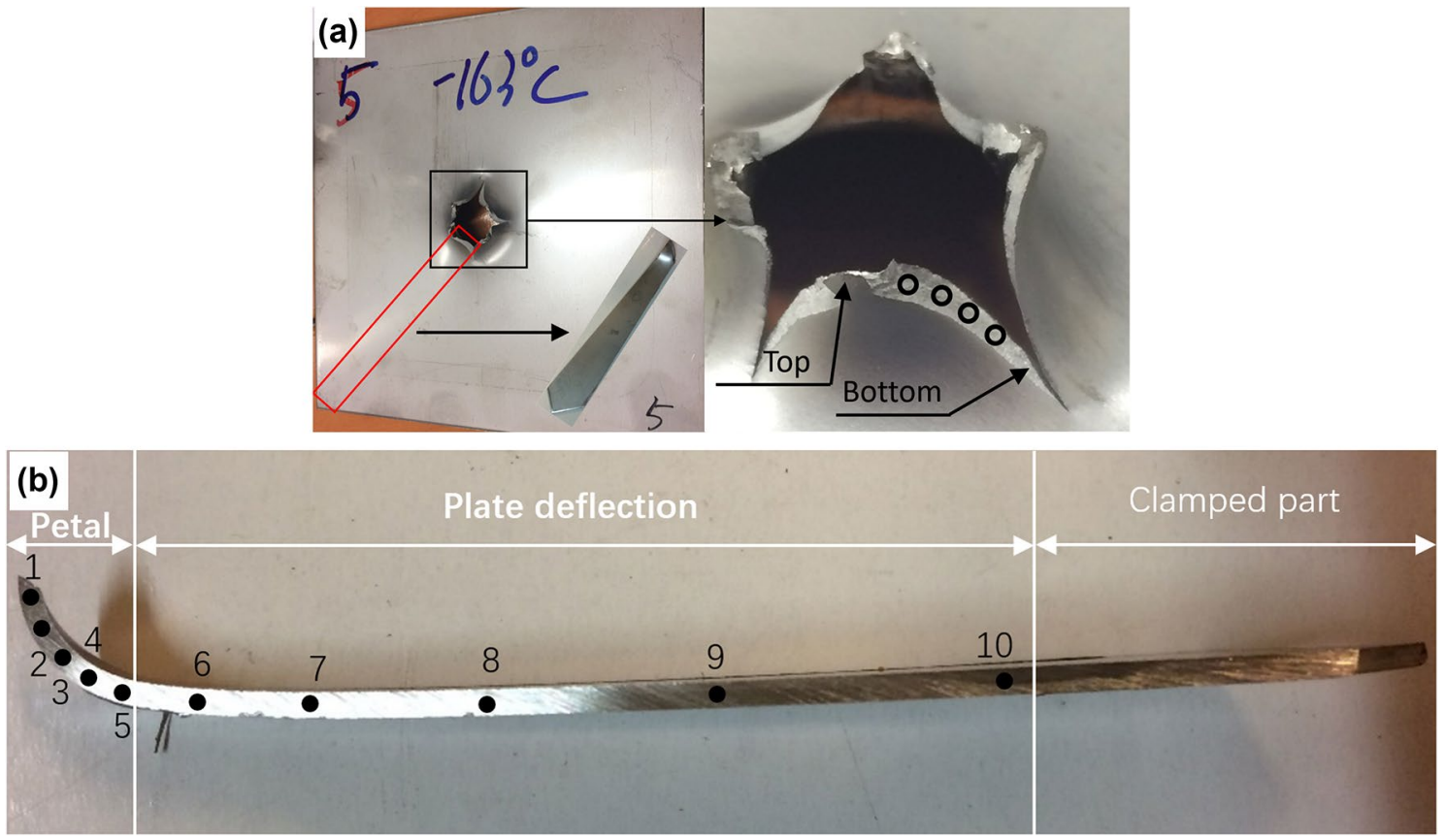

Fig. 17 Martensite measurement positions of the perforated specimens: $\mathbf{a}$ on the fracture surface of the petals and $\mathbf{b}$ along the cross-section of the plates 
(a)

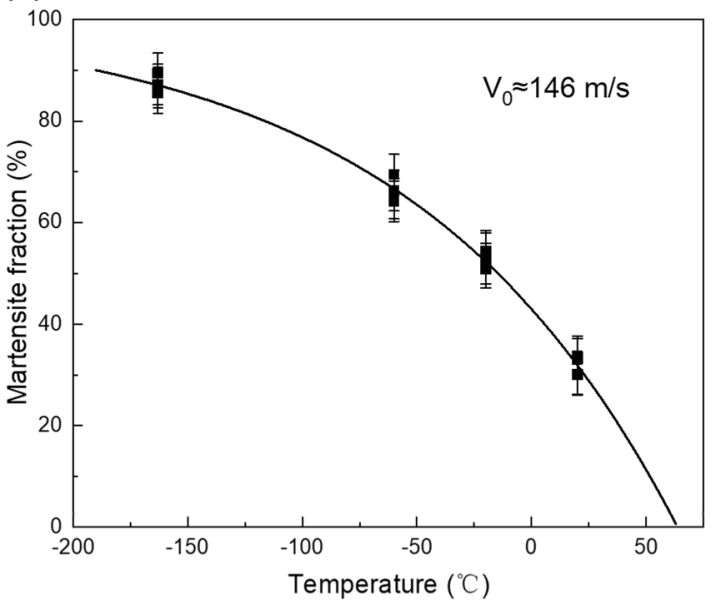

(b)

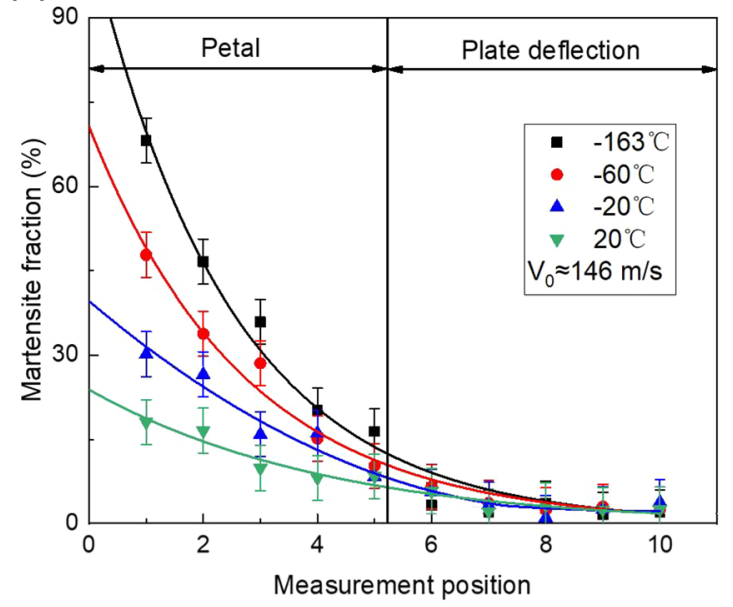

Fig. 18 Martensite fraction distribution of the perforated specimens: $\mathbf{a}$ on the fracture surface of the petals and $\mathbf{b}$ along the cross-section of the plates

the plate deflection part. What is more, in the petal part martensite fraction decreases quickly from the top of the petal to its bottom. Compared to the martensite fraction on the fracture surface of the petals, martensite inside the petals is obviously lower. This is mainly because the fracture surface corresponds to the maximum plastic deformation until failure while plastic deformation inside the petals is comparatively smaller.

\section{Conclusions and Remarks}

With a newly developed cooling device for ballistic impact device, influence of the temperature on perforation behavior of thin 304 ASS plates impacted by a conical projectile in the velocity range of 80 and $180 \mathrm{~m} / \mathrm{s}$ was studied. Based on experimental observations, the following conclusions are drawn:

- The cooling device helps to perform perforation tests at low temperatures ranging from -163 to $-20{ }^{\circ} \mathrm{C}$. Temperature uniformity on the plate surface is verified both experimentally and by numerical simulation. After a waiting time of $1200 \mathrm{~s}$, the maximum temperature fluctuation on the plate surface are $2{ }^{\circ} \mathrm{C}, 3^{\circ} \mathrm{C}, 4^{\circ} \mathrm{C}$ and $8{ }^{\circ} \mathrm{C}$ for testing temperature $-20{ }^{\circ} \mathrm{C},-40{ }^{\circ} \mathrm{C},-60{ }^{\circ} \mathrm{C}$ and $-163{ }^{\circ} \mathrm{C}$, respectively. If only the plate center (with a radius of $20 \mathrm{~mm}$ ) where plate deformation mainly occurs is considered, the maximum temperature fluctuations are $0.3{ }^{\circ} \mathrm{C}, 0.4{ }^{\circ} \mathrm{C}, 0.6{ }^{\circ} \mathrm{C}$ and $1.4{ }^{\circ} \mathrm{C}$, respectively.

- In the testing temperatures considered, petalling is the failure mode of the perforation process. The number of petals increases with decreasing testing temperature. The average number of petals is three at $20^{\circ} \mathrm{C}$ or $200{ }^{\circ} \mathrm{C}$, and increased continuously to five at $-163{ }^{\circ} \mathrm{C}$. The shape of the petals is also affected by the testing temperature: it looks like a regular triangle at $20^{\circ} \mathrm{C}$ and $200{ }^{\circ} \mathrm{C}$ while becomes rugged and discontinuous at lower temperatures.

- The ballistic limit velocity $V_{b l}$ is also affected by testing temperature. It increases slightly from $93 \mathrm{~m} / \mathrm{s}$ at $200{ }^{\circ} \mathrm{C}$ to $103 \mathrm{~m} / \mathrm{s}$ at $-20^{\circ} \mathrm{C}$ and then remains constant at even lower temperatures. Also, the ballistic curves $V_{0}-V_{R}$ are influenced by testing temperature. For $20{ }^{\circ} \mathrm{C}$ and $200{ }^{\circ} \mathrm{C}$, the ballistic curves seem to coincide when the initial projectile velocity is much higher than the ballistic limit velocity. The ballistic curves at $-20{ }^{\circ} \mathrm{C},-60{ }^{\circ} \mathrm{C}$ and $-163{ }^{\circ} \mathrm{C}$ are almost the same and slightly lower than that at $20^{\circ} \mathrm{C}$ and $200{ }^{\circ} \mathrm{C}$.

- Although the plastic deformation of target is smaller at lower testing temperatures, the energy absorption capacity of 304 ASS at low temperatures is obviously higher than at room or elevated temperatures. A high amount of martensite was observed in the perforated specimens, especially in the petals. The improved energy absorption capacity of 304 ASS at low temperatures comes from not only temperature sensitivity of the material but also the SIMT effect.

Acknowledgements This work of the first author was financially supported by China Scholarship Council under Grant 201606220056. Author from Agadir thanks M. Tomasz Libura from IPPT to participate in the construction of the device allowing to reach high temperatures under dynamic impact and perforation. The system has been developed in agreement between IPPT, Universiapolis Agadir and Lorraine University, patent no. 41383 Kingdom of Morocco (2017). 
1. Fischer FD, Sun Q-P, Tanaka K (1996) Transformation-induced plasticity (TRIP). Appl Mech Rev 49:317-364. https://doi. org/10.1115/1.3101930

2. Fischer FD, Reisner G, Werner E, Tanaka K, Cailletaud G, Antretter T (2000) A new view on transformation induced plasticity (TRIP). Int J Plast 16:723-748. https://doi.org/10.1016/S0749 -6419(99)00078-9

3. Kim J-H, Choi S-W, Park D-H, Lee J-M (2015) Charpy impact properties of stainless steel weldment in liquefied natural gas pipelines: effect of low temperatures. Mater. Des (1980-2015) 65:914-922. https://doi.org/10.1016/j.matdes.2014.09.085

4. Park WS, Chun MS, Han MS, Kim MH, Lee JM (2011) Comparative study on mechanical behavior of low temperature application materials for ships and offshore structures: part I-experimental investigations. Mater Sci Eng A 528:5790-5803. https://doi. org/10.1016/j.msea.2011.04.032

5. Jayahari L, Gangadhar J, Singh SK, Balunaik B (2017) Investigation of high temperature forming of ASS 304 using BARLAT 3-parameter model. Mater Today: Proc 4:799-804. https://doi. org/10.1016/j.matpr.2017.01.088

6. Sun G, Du L, Hu J, Zhang B, Misra RDK (2019) On the influence of deformation mechanism during cold and warm rolling on annealing behavior of a 304 stainless steel. Mater Sci Eng A 746:341-355. https://doi.org/10.1016/j.msea.2019.01.020

7. Børvik T, Langseth M, Hopperstad OS, Malo KA (1999) Ballistic penetration of steel plates. Int J Impact Eng 22:855-886. https:// doi.org/10.1016/S0734-743X(99)00011-1

8. Rusinek A, Rodríguez-Martínez JA, Zaera R, Klepaczko JR, Arias A, Sauvelet C (2009) Experimental and numerical study on the perforation process of mild steel sheets subjected to perpendicular impact by hemispherical projectiles. Int J Impact Eng 36:565-587. https://doi.org/10.1016/j.ijimpeng.2008.09.004

9. Antoinat L, Kubler R, Barou J-L, Viot P, Barrallier L (2015) Perforation of aluminium alloy thin plates. Int J Impact Eng 75:255267. https://doi.org/10.1016/j.ijimpeng.2014.07.017

10. Bendarma A, Jankowiak T, Łodygowski T, Rusinek A, Klósak $M$ (2017) Experimental and numerical analysis of the aluminum alloy AW5005 behavior subjected to tension and perforation under dynamic loading. J Theor Appl Mech 55:1219-1233. https://doi. org/10.15632/jtam-pl.55.4.1219

11. Rodríguez-Millán M, Vaz-Romero A, Rusinek A, Rodríguez-Martínez JA, Arias A (2014) Experimental study on the perforation process of 5754-H111 and 6082-T6 aluminium plates subjected to normal impact by conical hemispherical and blunt projectiles. Exp Mech 54:729-742. https://doi.org/10.1007/s11340-013-9829-z

12. Numata D, Ohtani K, Anyoji M, Takayama K, Togami K, Sun M (2008) HVI tests on CFRP laminates at low temperature. Int J Impact Eng 35:1695-1701. https://doi.org/10.1016/j.ijimp eng.2008.07.055

13. Børvik T, Hopperstad OS, Langseth M, Malo KA (2003) Effect of target thickness in blunt projectile penetration of Weldox $460 \mathrm{E}$ steel plates. Int J Impact Eng 28:413-464. https://doi.org/10.1016/ S0734-743X(02)00072-6

14. Goldsmith W, Finnegan SA (1986) Normal and oblique impact of cylindro-conical and cylindrical projectiles on metallic plates. Int J Impact Eng 4:83-105. https://doi.org/10.1016/0734743X(86)90010-2

15. Alavi Nia A, Hoseini GR (2011) Experimental study of perforation of multi-layered targets by hemispherical-nosed projectiles. Mater Des 32:1057-1065. https://doi.org/10.1016/j.matde s.2010.07.001
16. Børvik T, Hopperstad OS, Berstad T, Langseth M (2002) Perforation of $12 \mathrm{~mm}$ thick steel plates by $20 \mathrm{~mm}$ diameter projectiles with flat, hemispherical and conical noses: part II: numerical simulations. Int J Impact Eng 27:37-64. https://doi.org/10.1016/ S0734-743X(01)00035-5

17. Arias A, Rodríguez-Martínez JA, Rusinek A (2008) Numerical simulations of impact behaviour of thin steel plates subjected to cylindrical, conical and hemispherical non-deformable projectiles. Eng Fract Mech 75:1635-1656. https://doi.org/10.1016/j.engfr acmech.2007.06.005

18. Børvik T, Langseth M, Hopperstad OS, Malo KA (2002) Perforation of $12 \mathrm{~mm}$ thick steel plates by $20 \mathrm{~mm}$ diameter projectiles with flat, hemispherical and conical noses: part I: experimental study. Int J Impact Eng 27:19-35. https://doi.org/10.1016/S0734 $-743 \mathrm{X}(01) 00034-3$

19. Rodríguez-Martínez JA, Rusinek A, Pesci R, Zaera R (2013) Experimental and numerical analysis of the martensitic transformation in AISI 304 steel sheets subjected to perforation by conical and hemispherical projectiles. Int J Solids Struct 50:339-351. https://doi.org/10.1016/j.jisolstr.2012.09.019

20. Rusinek A, Rodriguez-Martinez JA, Pesci R, Capelle J (2010) Experimental characterisation and modelling of the thermo-viscoplastic behaviour of steel AISI 304 within wide ranges of strain rate at room temperature. J Theor Appl Mech 48(4):1027-1042

21. Ohtani K, Numata D, Kikuchi T, Sun M, Takayama K, Togami K (2006) A study of hypervelocity impact on cryogenic materials. Int J Impact Eng 33:555-565. https://doi.org/10.1016/j.ijimp eng.2006.09.025

22. Tanaka K, Nishida M, Takada N (2006) High-speed penetration of a projectile into aluminum alloys at low temperatures. Int J Impact Eng 33:788-798. https://doi.org/10.1016/j.ijimpeng.2006.09.089

23. Numata D, Ohtani K, Anyoji M, Takayama K, Sun M (2008) Experimental study of hypervelocity impacts at low temperatures. Shock Waves 18:169-183. https://doi.org/10.1007/s0019 3-008-0156-8

24. Tanaka K, Nishida M, Ogawa H, Akahori M, Aikawa F (2008) Hypervelocity crater formation in aluminum alloys at low temperatures. Int J Impact Eng 35:1821-1826. https://doi.org/10.1016/j. ijimpeng.2008.07.043

25. Rodríguez-Martínez JA, Rusinek A, Arias A (2011) Thermoviscoplastic behaviour of 2024-T3 aluminium sheets subjected to low velocity perforation at different temperatures. Thin-Walled Struct 49:819-832. https://doi.org/10.1016/j.tws.2011.02.007

26. Rodríguez-Martínez JA, Pesci R, Rusinek A, Arias A, Zaera R, Pedroche DA (2010) Thermo-mechanical behaviour of TRIP 1000 steel sheets subjected to low velocity perforation by conical projectiles at different temperatures. Int J Solids Struct 47:12681284. https://doi.org/10.1016/j.ijsolstr.2010.01.013

27. Rusinek A, Bernier R, Boumbimba RM, Klosak M, Jankowiak T, Voyiadjis GZ (2018) New devices to capture the temperature effect under dynamic compression and impact perforation of polymers, application to PMMA. Polym Test 65:1-9. https://doi. org/10.1016/j.polymertesting.2017.10.015

28. Liu J, Zheng B, Zhang K, Yang B, Yu X (2019) Ballistic performance and energy absorption characteristics of thin nickel-based alloy plates at elevated temperatures. Int J Impact Eng 126:160171. https://doi.org/10.1016/j.ijimpeng.2018.12.012

29. Erice B, Gálvez F, Cendón DA, Sánchez-Gálvez V, Børvik T (2011) An experimental and numerical study of ballistic impacts on a turbine casing material at varying temperatures. J Appl Mech 78:051019. https://doi.org/10.1115/1.4004296

30. Klosak M, Rusinek A, Bendarma A, Jankowiak T, Lodygowski T, Klosak M et al (2018) Experimental study of brass properties through perforation tests using a thermal chamber for 
elevated temperatures. Latin Am J Solids Struct. https://doi. org/10.1590/1679-78254346

31. Rodriguez-Millan M, Garcia-Gonzalez D, Rusinek A, Abed F, Arias A (2018) Perforation mechanics of 2024 aluminium protective plates subjected to impact by different nose shapes of projectiles. Thin-Walled Struct 123:1-10. https://doi.org/10.1016/j. tws.2017.11.004

32. Duthil P (2015) Material properties at low temperature. arXiv:150107100 [Cond-Mat, Physics: Physics]. https://doi. org/10.5170/cern-2014-005.77

33. Jankowiak T, Rusinek A, Wood P (2013) A numerical analysis of the dynamic behaviour of sheet steel perforated by a conical projectile under ballistic conditions. Finite Elem Anal Des 65:39-49. https://doi.org/10.1016/j.finel.2012.10.007

34. Recht RF, Ipson TW (1963) Ballistic perforation dynamics. J Appl Mech 30:384-390. https://doi.org/10.1115/1.3636566

35. Pérez-Castellanos J-L, Rusinek A (2012) Temperature increase associated with plastic deformation under dynamic compression: application to aluminium alloy Al 6082. J Theor Appl Mech 50:377-398

36. Park WS, Yoo SW, Kim MH, Lee JM (2010) Strain-rate effects on the mechanical behavior of the AISI 300 series of austenitic stainless steel under cryogenic environments. Mater Des 31:36303640. https://doi.org/10.1016/j.matdes.2010.02.041

37. Standard A (2008) E975-03: standard practice for X-ray determination of retained austenite in steel with near random crystallographic orientation. ASTM, West Conshohocken

38. Beese AM, Mohr D (2011) Effect of stress triaxiality and Lode angle on the kinetics of strain-induced austenite-to-martensite transformation. Acta Mater 59:2589-2600. https://doi. org/10.1016/j.actamat.2010.12.040

39. Byun TS, Hashimoto N, Farrell K (2004) Temperature dependence of strain hardening and plastic instability behaviors in austenitic stainless steels. Acta Mater 52:3889-3899. https://doi. org/10.1016/j.actamat.2004.05.003

40. Talonen J, Hänninen H (2007) Formation of shear bands and strain-induced martensite during plastic deformation of metastable austenitic stainless steels. Acta Mater 55:6108-6118. https:// doi.org/10.1016/j.actamat.2007.07.015

41. Hamada AS, Karjalainen LP, Misra RDK, Talonen J (2013) Contribution of deformation mechanisms to strength and ductility in two $\mathrm{Cr}-\mathrm{Mn}$ grade austenitic stainless steels. Mater Sci Eng A 559:336-344. https://doi.org/10.1016/j.msea.2012.08.108

42. Zaera R, Rodríguez-Martínez JA, Casado A, Fernández-Sáez J, Rusinek A, Pesci R (2012) A constitutive model for analyzing martensite formation in austenitic steels deforming at high strain rates. Int J Plast 29:77-101. https://doi.org/10.1016/j.ijpla s.2011.08.003

43. Rodríguez-Martínez JA, Rusinek A, Pesci R (2010) Experimental survey on the behaviour of AISI 304 steel sheets subjected to perforation. Thin-Walled Struct 48:966-978. https://doi. org/10.1016/j.tws.2010.07.005

44. Nazeer MM, Khan MA, Naeem A, Haq A (2000) Analysis of conical tool perforation of ductile metal sheets. Int J Mech Sci 42:1391-1403. https://doi.org/10.1016/S0020-7403(99)00065-X

45. Kpenyigba KM, Jankowiak T, Rusinek A, Pesci R (2013) Influence of projectile shape on dynamic behavior of steel sheet subjected to impact and perforation. Thin-Walled Struct 65:93-104. https://doi.org/10.1016/j.tws.2013.01.003 